\title{
Mapping users' expectations regarding extended-range forecasts
}

\author{
Tiina Ervasti, Hilppa Gregow, Andrea Vajda, Terhi K. Laurila, and Antti Mäkelä \\ Finnish Meteorological Institute, P.O. Box 503, 00101 Helsinki, Finland \\ Correspondence: Tiina Ervasti (tiina.ervasti@fmi.fi)
}

Received: 16 January 2018 - Revised: 28 March 2018 - Accepted: 9 April 2018 - Published: 28 May 2018

\begin{abstract}
An online survey was used to map the needs and preferences of the Finnish general public concerning extended-range forecasts and their presentation. First analyses of the survey were used to guide the co-design process of novel extended-range forecasts to be developed and tested during the project. In addition, the survey was used to engage the respondents from the general public to participate in a one year piloting phase that started in June 2017. The respondents considered that the tailored extended-range forecasts would be beneficial in planning activities, preparing for the weather risks and scheduling the everyday life. The respondents also perceived the information about the impacts of weather conditions more important than advice on how to prepare for the impacts.
\end{abstract}

\section{Introduction}

As part of developing the climate services, much focus has been put on the extended-range forecasts (ERF; up to 46 days) and long-range or seasonal forecasts (LRF; 17 months). For instance, in the FP7 project CORE-CLIMAX (Gregow et al., 2016b; Su et al., 2017) it was found, based on a worldwide survey, that in addition to homogenized climate data records monthly and seasonal forecasting are considered important in the development of future climate services. Additionally, the impact assessments for improving weather warnings and their criteria were considered desirable. Also, based on the findings of project ELASTINEN (Gregow et al., 2016a; Pilli-Sihvola et al., 2016; Harjanne et al., 2017), one of the recommendations given to the Finnish Government was that impact-based forecasts and warnings are relevant for decision-making related to climate change adaptation.

The use of ERF and LRF in decision-making processes is still relatively new in Europe and fairly underutilized or not used at all in many sectors (Bruno Soares and Dessai, 2016; Soares et al., 2017). One reason for this is the low reliability and skill of the forecasts in Europe. Also there is a lack of awareness that such forecasts are available and sometimes the content of information provided by the forecasts is ineffective (Bruno Soares and Dessai, 2016). Although there are many challenges remaining, the progress in developing the
ERF and LRF forecasts is fast. This improves the opportunities of developing user-oriented climate services (Vitart et al., 2017).

Finnish Meteorological Institute (FMI) has been using the long-range forecasts of ECMWF (the European Centre for Medium-Range Weather Forecasts) for years. However, the use has been mostly non-operational and the outlooks for the general public have been provided in text format on the FMI website, therefore not engaging the public much in the development of the services. Furthermore, only a few casestudy verifications have been made (Hyvärinen et al., 2017) for showing the capability and usefulness of these forecasts for the Finnish society.

Buontempo et al. (2014) especially emphasize the need to maintain the dialogue between providers and users of climate information when developing the climate services. In CLIPSproject (CLImate services supporting Public activities and Safety, 2016-2018) user engagement is in the heart of developing extended-range forecast services and piloting them with users from the general public. The survey presented in this paper was launched at the planning stages of the ERF services and it was the first step in the co-design process of the project. The aim was to map the users' needs and preferences in detail and use the responses from the survey to guide the design process of the first forecast prototypes. In the sec- 


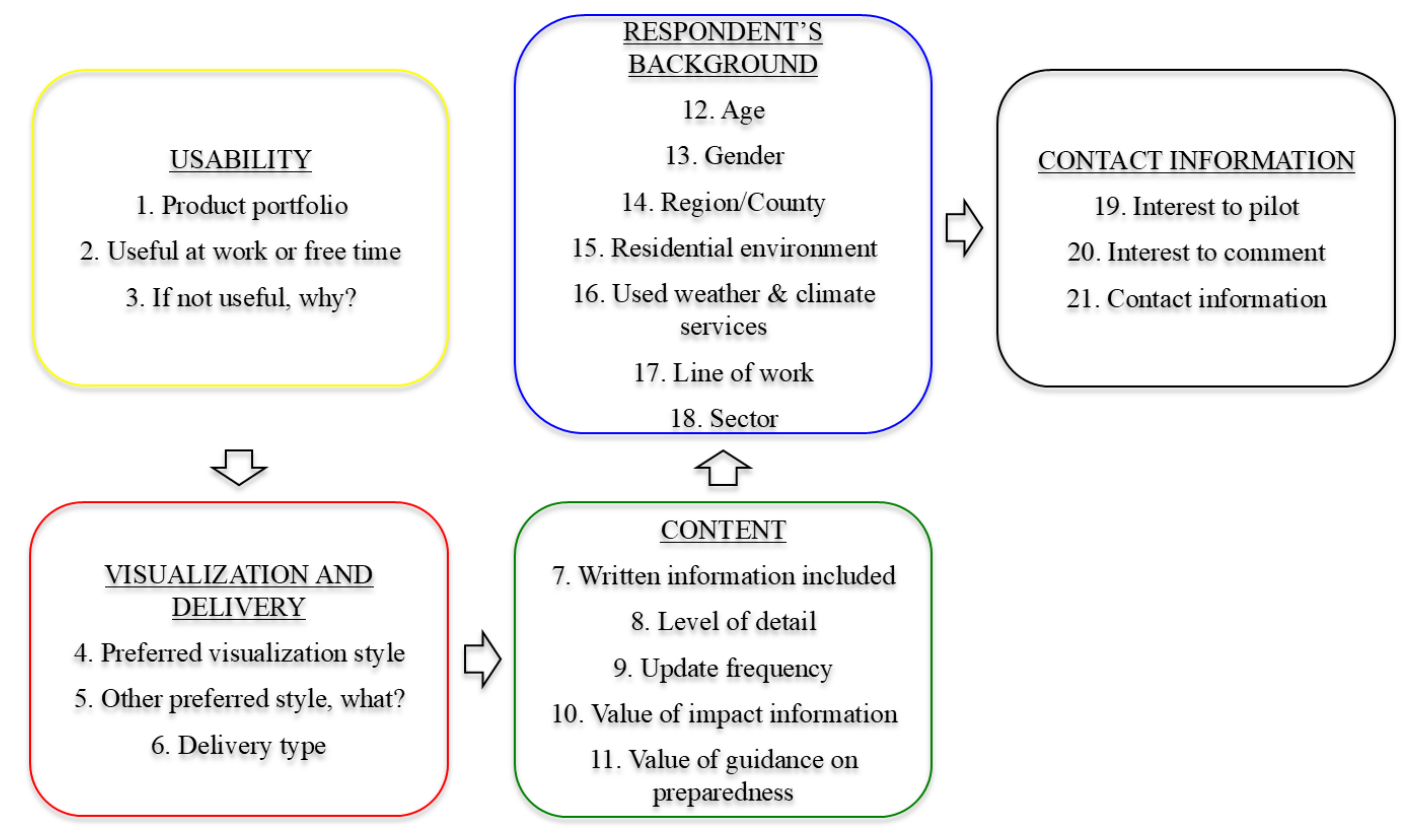

Figure 1. The survey structure consisted of five thematic sections: usability (yellow), visualization and delivery (red), content (green), respondent's background (blue), contact information (black). Depending on the previous answers, not all questions had to be answered.

ond step of the co-design process pilot users test seasonally tailored extended-range forecasts for Finland. In this piloting phase of the CLIPS-project (June 2017-May 2018) the outcome of the CLIPS online survey can also be further verified and expanded on. Also, a website was designed to provide information and news, for instance about lessons learned, to improve the dialogue.

In this paper, we present some outcomes of this survey and our first attempts to co-design extended-range forecast services within the CLIPS-project. We will specifically focus on how users estimated they could benefit from the ERF products and services, and whether they appreciate the aspect that the impact information is built-in in the ERF service. Based on the analyses and discussions presented in this paper, we hope to be able to provide new insights of the user perspective for future development of weather and climate services.

\section{Study design}

The CLIPS online survey was targeted at the Finnish general public. It was structured in five sections and consisted of maximum 21 questions (Fig. 1). The sections included questions about usability and preferences for certain tailored ERF products, visualization and delivery of the ERF products, content of the ERF products, background information of the respondents, and willingness to pilot the novel ERF services.

In the beginning of the survey a set of 28 ERF products was presented for the summer, autumn, winter and spring seasons to give the respondents an idea of the possible prod- ucts (see Appendix A). Product portfolio contained descriptive names of the possible products, but no visualized examples or detailed information of the content. In this paper we focus on the aspect of how users think they could benefit from ERF products. The survey questions that contribute to this aspect and are analyzed in more detail are listed in Table 1 (questions 2, 10 and 11). Question 2 had seven readymade options (see Table 4) and an open field to provide the respondents the choice of giving their own answer. Respondents were able to choose as many potential benefits as they wished. Respondents could also elaborate whether they would benefit of the forecasts in their work, free time or in both occasions. Questions 10 and 11 were based on ratingscale: I consider it very important, I consider it somewhat important, I consider it not that important, I don't need this kind of information.

The CLIPS online survey was distributed to the Finnish public with two-folded approach to reach as many respondents as possible. The two-folded distribution approach included (1) general communication channels, such as website and social media channels of FMI and the CLIPS project's own website (http://clips.fmi.fi, 24 April 2018) and (2) more than 100 national and regional organizations, institutions, and associations, whose members could potentially benefit from ERF products. Therefore, the targeted users also covered economic and social sectors such as health, education, tourism, transportation, forestry, agriculture, rescue services, civil engineering departments of major cities, and various sport or outdoor organizations. The survey was opened to public for 10 weeks during 23 March-5 June 2017. 
Table 1. Questions from the survey about how users estimate to benefit of the extended-range forecast products.

\begin{tabular}{lr}
\hline Question & Respondents/Total \\
\hline (2) Please estimate, in which way extended-range forecasts could benefit you. & $406 / 408$ \\
(10) How important it is for you that the forecast includes information & $401 / 408$ \\
on the impacts of weather conditions. & \\
(11) How important it is for you that the forecast includes information on how & $402 / 408$ \\
to prepare for the impacts of weather conditions. &
\end{tabular}

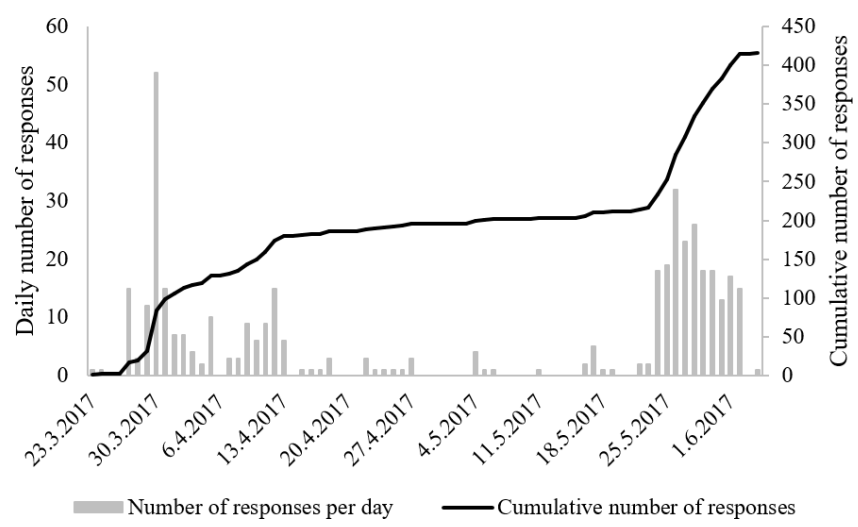

Figure 2. The rate of responses received on CLIPS online survey during the 10 weeks open period.

The promoting of the project was combined with distributing the survey. Following steps were involved: (i) emailing about the survey and the following pilot phase with targeted invitation letters that were sent during 23-30 March 2017, (ii) promoting the CLIPS online survey in the social media channels of FMI, including FMI Beta (Facebook page) and FMI's Twitter channel focused on research and science topics (which has currently 6521 followers), (iii) launching the CLIPS project website http://clips.fmi.fi on 9 May 2017, (iv) releasing a press release about CLIPS and the ongoing survey on FMI main website on 16 May and sharing it in the FMI social media channels, (v) placing CLIPS-project teaser on the website of the FMI long-range forecasts with a title "Forecasts for 6 weeks?". The results of these communication and dissemination efforts are presented in Fig. 2, where especially steps (i), (ii), and (iv) show as visible leaps in the number of responses.

\subsection{Extended-range forecast prototypes developed in the project}

The CLIPS online survey was aimed at guiding the development of extended-range forecast prototypes for the pilot phase of the project. Based on the survey results, the ERF prototypes were then improved and made more user-friendly based on the opinions of the general public. When the survey was launched, the prototypes were still in the development phase and not available to the respondents. However, some (a)
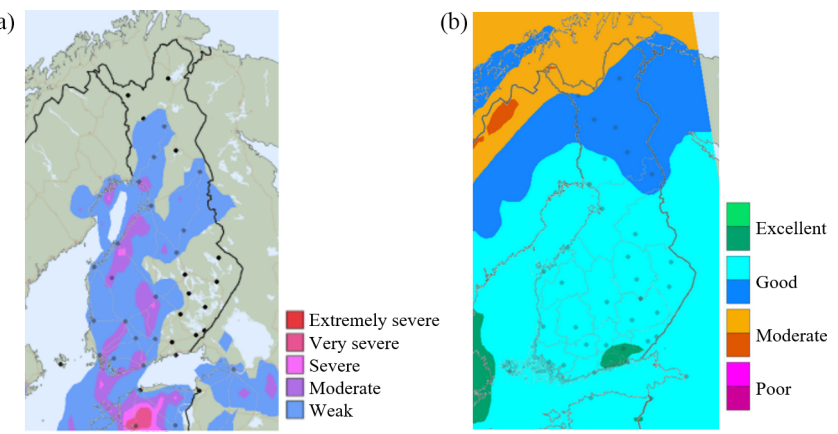

Figure 3. Two examples of extended-range impact forecast prototypes. Thunderstorm outlook (a) and sport weather outlook (b).

basic guidelines were already set and we describe them here to give an idea of the planned ERF products.

The prototypes were based on the 0-46 day ERF data from the ECMWF (all 50 ensemble members). Additionally, the hours 00:00, 06:00, 12:00, 18:00 UTC were available when tailoring the forecasts. The forecasts were presented as weekly means and extremes for those hours that played an important role for the activities it was tailored for.

Here we describe two examples of the extended-range impact forecast prototypes in the planning phase: thunderstorm and sport weather outlooks (Fig. 3). The thunderstorm outlook was designed to demonstrate the risk for thunder and lightning using a five-point severity scaling. On a map of the Nordic countries we showed if the forecast indicated a risk for weak, moderate, severe, very severe or extremely severe thunderstorm and lightning in the coming weeks. The outlook was a combination of weekly mean CAPE (Convective Available Potential Energy) anomaly and historical lightning data of the Finnish Meteorological Institute. First, a weekly statistical lightning map was produced and then, the map was modified based on CAPE anomaly forecast. The sports weather outlook was communicated differently. It presented the impact of weather conditions on the possibilities to perform outdoor sports using four categories: Poor (Pink), Moderate (Orange), Good (Blue) and Excellent (Green). Sports weather index included wind speed (WS), temperature $(T)$ and relative humidity (RH) between 09:00 am-09:00 pm local time. 


\section{Results}

The CLIPS online survey resulted in 416 responses in total. However, eight respondents considered not to be interested in the planned extended-range forecasts and no further questions were asked from them. Therefore, the sample of 408 replies is used as the data set. As some respondents left some questions blank or unanswered the amount of replies varies between the questions as addressed in Table 1 .

\subsection{Background information of the respondents}

The sample covered wide range of the general public. $63 \%$ of the respondents were male and $36 \%$ female, the rest did not want to express their gender. The most represented age groups were 50-59 (26\%), 40-49 (24\%), 30-39 (20\%), 60$69(18 \%)$, in that order, but the sample involved all age groups. In addition, the sample covered all regions of Finland except Åland region, even though the Uusimaa region (capital area) was slightly overrepresented in the sample with $30 \%$ share. The respondents also came from various different residential environments as $29 \%$ lived in large cities (over 100000 inhabitants) or in their suburbs $(9 \%), 24 \%$ in small or medium-sized cities (20000-100000 inhabitants), $17 \%$ in smaller population centers and $21 \%$ in the rural areas that are sparsely populated. Over $90 \%$ of the respondents stated that they use some kind of weather forecasts, $80 \%$ some kind of monthly forecast product and $50 \%$ some kind of seasonal forecast product. Only $8 \%$ replied that they had not used these types of forecasts. When asked which of the currently provided long-range forecast services the respondents knew and were using already, the three most mentioned were the FMI monthly forecasts, the FMI seasonal forecasts and other providers' monthly forecasts (Table 2).

\subsection{Preferences on the product portfolio}

In the survey a set of 28 possible products was presented for summer, autumn, winter and spring (question 1 in Fig. 1, full list in Appendix A). The most popular were the sweater weather outlook (cold spells), winter tire outlook, thunderstorm outlook, probability of difficult traffic conditions, and growing season outlook (Table 3). This information and feedback related to possible benefits of these product examples were considered when further working on the pilot product prototypes for each season.

\subsection{Estimated benefits from using tailored extended-range forecasts}

Most of the respondents were already familiar with some kind of monthly and seasonal forecasts (Table 2) and showed interest in the possible ERF products presented in the survey (Table 3). Respondents were then asked to estimate how they would benefit from the novel tailored extended-range forecasts (question 2, Table 1). The three most popular options were: help in planning activities, help in preparing for weather risks and making everyday life easier (Table 4). In addition, two benefits were commonly described under the option "other": help in scheduling activities and generally following the coming weather conditions.

The order of most commonly chosen benefits was very similar between aspects of work and free time. Economical benefit was the only one that was more often related to work than to free time use. In general, $56 \%$ of the respondents chose at least one work-related benefit gained from using extended-range forecasts. In contrast to this, over $90 \%$ chose at least one potential benefit linked with their free time. Thus, respondents more commonly estimated to benefit from extended-range forecasts on their free time rather than at work.

The respondents, who stated they would benefit from ERF products in their work, worked mainly in private organizations $(53 \%)$ but also in municipalities $(17 \%)$, other governmental organizations (19\%), or non-governmental organizations $(6 \%)$. They represented over 27 different fields of work, the most common being agriculture and food production, education, and traffic and infrastructure.

All respondents were also asked to rate, how important it is for them that impact and/or preparedness-related information is coupled with the extended-range forecast (questions 10 and 11, Table 1). As seen in Fig. 4 the responses indicated that almost $40 \%$ of the respondents thought that it is very important to get information on the possible impacts of weather conditions. Approximately as many considered that it is at least somewhat important. On the other hand, only about $20 \%$ of the respondents considered it very important to include guidance on how to prepare for the impacts, and $30 \%$ of the respondents considered it somewhat important.

\section{Discussion}

The CLIPS online survey was designed to support the product development process and to be exploratory and open in nature. Therefore the outcome can not be generalized to represent the opinions of the whole Finnish general public. However, it provides a new insight in the needs of the general public, as extended-range and long-range forecast products are often targeted at certain professional sectors. Therefore most available information comes from the surveys or codesign processes with targeted professional sectors and not general audiences.

In the survey over $80 \%$ of the respondents stated they used some kind of monthly forecast product and over $50 \%$ some kind of seasonal forecast product. As monthly and seasonal forecast products are often considered to be less used by the general public, it can be assumed that a lot of respondents took the survey as they were interested in the topic of extended-range forecasts to begin with. 
Table 2. The provider and the type of long-range forecast that the respondents $(N=408)$ were familiar with.

\begin{tabular}{lrr}
\hline Type of long-range forecasts used by the respondents & Responses & Response percentage \\
\hline FMI monthly forecast & 306 & $75 \%$ \\
FMI seasonal forecast & 189 & $46 \%$ \\
Other provider's monthly forecast & 152 & $37 \%$ \\
Other provider's seasonal forecast & 65 & $16 \%$ \\
Monthly forecast tailored for your organization & 8 & $2 \%$ \\
Seasonal forecast tailored for your organization & 4 & $1 \%$ \\
Other forecast tailored for your organization & 13 & $3 \%$ \\
I do not use long-range forecasts & 31 & $8 \%$ \\
\hline
\end{tabular}

Table 3. The ten most popular products presented in the survey's product portfolio ordered by popularity.

\begin{tabular}{|c|c|c|c|}
\hline ERF product & Season & $\begin{array}{l}\text { Times chosen in the responses } \\
\qquad(N=408)\end{array}$ & Response percentage \\
\hline Sweater weather outlook (cold spells) & Winter & 265 & $65 \%$ \\
\hline Winter tire outlook & Autumn & 241 & $59 \%$ \\
\hline Thunderstorm outlook & Summer & 230 & $56 \%$ \\
\hline Probability of difficult traffic conditions & Winter & 229 & $56 \%$ \\
\hline Growing season outlook & Summer & 212 & $52 \%$ \\
\hline Probability of slippery road conditions & Winter & 210 & $51 \%$ \\
\hline Forest outdoor activity conditions & Autumn & 200 & $49 \%$ \\
\hline Winter sport outlook & Winter & 183 & $45 \%$ \\
\hline Probability of sultry heat spells & Summer & 163 & $40 \%$ \\
\hline Outlook for gravel removal & Spring & 133 & $33 \%$ \\
\hline
\end{tabular}

Also, respondents estimated more commonly to benefit from tailored extended-range forecasts on their free time rather than at work. This suggests that also users outside usually targeted professional sectors think they could benefit from extended-range forecasts. The respondents from the general public also rated the impact information higher than guidance on how to prepare for these impacts.

The aim of the survey was to map the users' perspective in more detail and use the outcome to guide the design process of the first forecast prototypes. Based on the survey, we were able to choose the most interesting tailored ERF products to be tested and to improve our already-planned ERF products (Fig. 3). The feedback related to possible benefits linked with the product examples were considered when further working on the prototypes for each season. We also managed to engage the first 200 pilot users to test the ERF prototypes through the survey. The outcome of the survey also supports us in assessing the experiences of users before and after the piloting phase of the project.

In the future, more information on the users will be gathered in the piloting phase of the CLIPS project, in which pilot users will test various tailored extended-range forecasts in practice and give feedback. Combining the results of the CLIPS online survey and the feedback from piloting provides a larger data set, in which the user needs of ERF products can be more closely mapped. For instance, one option would be to consider whether different demographic variables had an effect on how the respondents perceived the potential benefits of extended-range forecasts or the value of impact and preparedness-related information. These demographic variables cover for example the residential environment (large city, suburb, rural area etc.) as people generally use distinct means of transportation when commuting from different kinds of residential environments. Outcomes could indicate that some groups of the general public might benefit even more explicitly of climate services of this kind or they might have special needs regarding the forecasts.

\section{Conclusions}

From the previous projects CORE-CLIMAX (Gregow et al., 2016b; Su et al., 2017) and ELASTINEN (Gregow et al., 2016a; Pilli-Sihvola et al., 2016; Harjanne et al., 2017), we had learned that the ERF and LRF services as well as impact forecast are desired part of the climate services. Thus, with the CLIPS online survey, we wanted to better understand the details for tailoring these kinds of services for the public. According to the views of the 408 respondents the potential benefits of the ERF services are: (1) better understanding of the possible weather related risks and (2) aid in preparing for weather conditions and their likely impacts. Additionally, respondents of the CLIPS online survey most commonly chose 
Table 4. Potential benefits considered by the respondents $(N=406)$ if using the tailored extended range forecast products presented in the survey's product portfolio. The percentages indicate the share of respondents that chose the benefit.

\begin{tabular}{lrrrr}
\hline Potential benefit considered by the respondent & Free time & Work & Free time & Work \\
\hline Help in planning activities & 318 & 155 & $78 \%$ & $38 \%$ \\
Help in preparing for weather risks & 263 & 156 & $65 \%$ & $38 \%$ \\
Making everyday life easier & 244 & 121 & $60 \%$ & $30 \%$ \\
Increased feeling of safety & 187 & 87 & $46 \%$ & $21 \%$ \\
Economic benefit & 74 & 99 & $18 \%$ & $24 \%$ \\
Other & 42 & 14 & $10 \%$ & $3 \%$ \\
No benefit & 2 & 5 & $0 \%$ & $1 \%$ \\
\hline
\end{tabular}

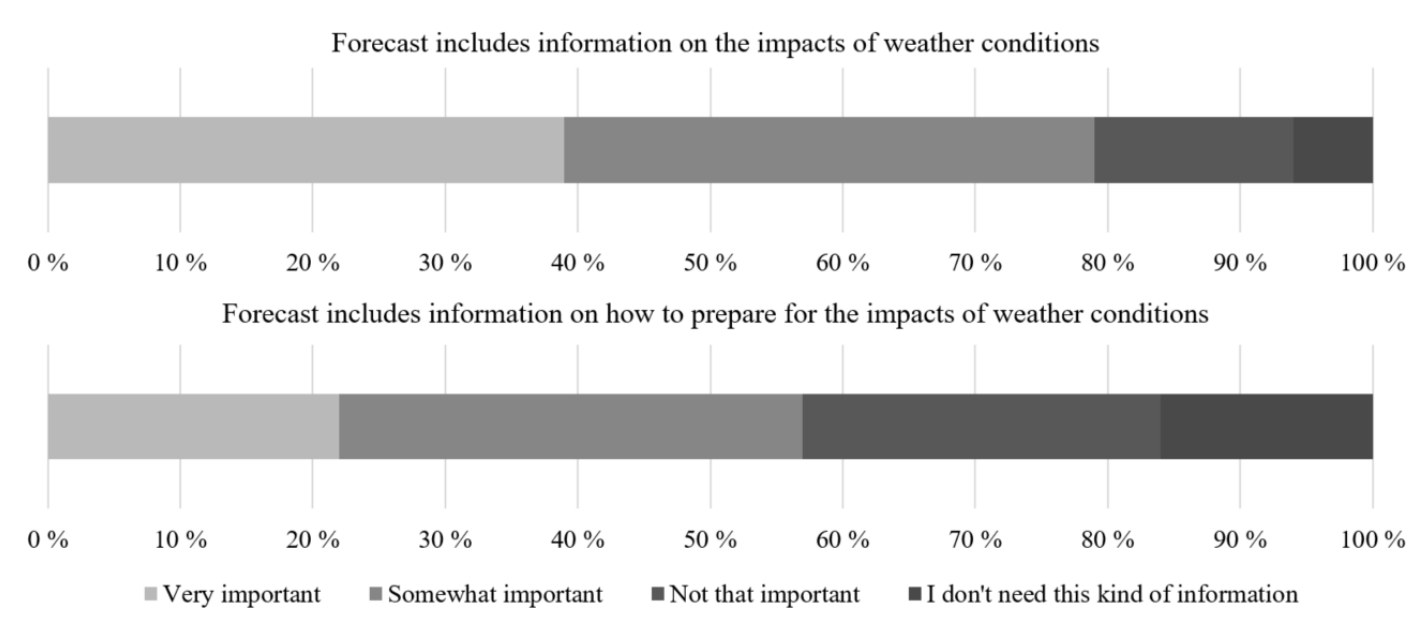

Figure 4. Rated value of built-in impact information compared to preparedness-related information in extended-range forecasts.

that they would benefit from ERF products when planning their free time activities although work-related benefits were also considered possible. Based on these findings, the piloting phase of the CLIPS project started with focus on tailoring ERF products and services that would indicate the risks and the possibilities with built-in information about the impacts of weather. The results of the CLIPS online survey are being further developed and verified during the piloting phase of the CLIPS-project (June 2017-May 2018), when registered users test seasonally tailored extended-range forecasts. Thus, in the future, it is possible to study the perceptions and needs with respondents who are piloting the novel extended-range forecast services in practice.
Data availability. The survey data is available only in Finnish and is at the moment not publicly archived as the project is still ongoing. However the survey was partially translated, as applicable, and those parts were included to support the analysis and conclusions presented in this paper. 
Appendix A

Table A1. Product portfolio of the possible tailored extended-range forecasts presented in the CLIPS online survey.

\begin{tabular}{ll}
\hline ERF product & Season \\
\hline Biking weather outlook & Summer \\
Outdoor sport conditions & Summer \\
Probability of increased forest fire risk & Summer \\
Thunderstorm outlook & Summer \\
Probability of sultry heat spells & Summer \\
Outlook for blue algae growth conditions in lakes & Summer \\
Growing season outlook & Summer \\
Skiing season outlook & Autumn \\
Biking weather outlook & Autumn \\
Outdoor sport conditions & Autumn \\
Outdoor sport conditions in water areas & Autumn \\
Forest outdoor activity conditions & Autumn \\
Outlook for autumn foliage & Autumn \\
Outlook for soil bearing capacity (roads) & Autumn \\
Winter tire outlook (probability of slippery driving conditions) & Autumn \\
Summer cottage season outlook (ending) & Autumn \\
Winter sport outlook & Winter \\
Winter biking outlook & Winter \\
Sweather weather outlook (probability of cold spells) & Winter \\
Probability of slippery road conditions & Winter \\
Probability of difficult traffic conditions & Winter \\
Biking weather outlook & Spring \\
Outdoor sport conditions & Spring \\
Growing season outlook & Spring \\
Probability of flooding roads & Spring \\
Probability of frost heave (soil bearing capacity, roads) & Spring \\
Summer cottage season outlook (beginning) & Spring \\
Outlook for gravel removal & Spring \\
\hline
\end{tabular}


Author contributions. TE and HG planned the paper together. All authors took part in the survey construction, survey analyses and/or writing.

Competing interests. The authors declare that they have no conflict of interest.

Special issue statement. This article is part of the special issue "17th EMS Annual Meeting: European Conference for Applied Meteorology and Climatology 2017”. It is a result of the EMS Annual Meeting: European Conference for Applied Meteorology and Climatology 2017, Dublin, Ireland, 4-8 September 2017.

Acknowledgements. This work was supported by the Academy of Finland, project number 303951 (SA CLIPS). We thank ECMWF collaborators Erik Andersson, Laura Ferranti, David Richardson, Tim Hewson and Ivan Tsonevsky for their valuable support in the project. Authors want to thank Juha A. Karhu, Otto Hyvärinen, Hannele Kaija and the Customer Services department of FMI for their useful comments in the planning phase and the volunteers who acted as the test general public before launching the survey. Also, Hadassa Hovestadt is acknowledged for helping in the analysis of survey results. Big thanks to all those Finns, who replied to the survey and gave their valuable opinion for us to work with.

Edited by: Carlo Buontempo

Reviewed by: Isadora Christel Jiménez and one anonymous referee

\section{References}

Bruno Soares, M. and Dessai, S.: Barriers and enablers to the use of seasonal climate forecasts amongst organisations in Europe, Climate Change, 137, 89-103, https://doi.org/10.1007/s10584-0161671-8, 2016.

Buontempo, C., Hewitt, C. D., Doblas-Reyes, F. J., and Dessai, S.: Climate service development, delivery and use in Europe at monthly to inter-annual timescales, Climate Risk Management, 6, 1-5, https://doi.org/10.1016/j.crm.2014.10.002, 2014.

Gregow, H., Carter, T., Groundstroem, F., Haavisto, R., Haanpää, S., Halonen, M., Harjanne, A., Hildén, M., Jakkila, J., Juhola, S., Jurgilevich, A., Kokko, A., Kollanus, V., Lanki, T., Luhtala, S., Miettinen, I., Mäkelä, A., Nurmi, V., Oljemark, K., Parjanne, A., Peltonen-Sainio, P., Perrels, A., Pilli-Sihvola, K., Punkka, A.-J., Raivio, T., Räsänen, A., Säntti, K., Tuomenvirta, H., Veijalainen, N., and Zacheus, O.: Keinot edistää sää- ja ilmastoriskien hallintaa, (Measures to promote the management of weather and climate related risks), Valtioneuvoston selvitysja tutkimustoiminnan julkaisusarja, 47/2016, 36 pp., 2016a (abstract in English).
Gregow, H., Jylhä, K., Mäkelä, H. M., Aalto, J., Manninen, T., Karlsson, P., Kaiser-Weiss, A. K., Kaspar, F., Poli, P., Tan, D. G. H., Obregon, A., and Su, Z.: Worldwide Survey of Awareness and Needs Concerning Reanalyses and Respondents Views on Climate Services, B. Am. Meteorol. Soc., 97, 1461-1473, https://doi.org/10.1175/BAMS-D-14-00271.1, $2016 \mathrm{~b}$.

Harjanne, A., Haavisto, R., Tuomenvirta, H., and Gregow, H.: Risk management perspective for climate service development - Results from a study on Finnish organizations, Adv. Sci. Res., 14, 293-304, https://doi.org/10.5194/asr-14-293-2017, 2017.

Hyvärinen, O., Mäkelä, A., Kämäräinen, M., and Gregow, H.: Long-range forecasts for the energy market - a case study, Adv. Sci. Res., 14, 89-93, https://doi.org/10.5194/asr-14-892017, 2017.

Pilli-Sihvola, K., Haavisto, R., Nurmi, V., Oljemark, K., Tuomenvirta, H., Groundstroem, F., Juhola, S., Miettinen, I., and Gregow, H.: Taloudellisesti tehokkaampaa sää- ja ilmastoriskien hallintaa Suomessa, (Efficient weather and climate risk management in Finland), Valtioneuvoston selvitys- ja tutkimustoiminnan julkaisusarja, 45/2016, 68 pp., 2016 (abstract in English).

Soares, M. B., Alexander, M., and Dessai, S.: Sectoral use of climate information in Europe: A synoptic overview, Climate Services, 9, 5-20, https://doi.org/10.1016/j.cliser.2017.06.001, 2017.

Su, Z., Timmermans, W., Zeng, Y., Schulz, J., John, V., Roebeling, R., Poli, P., Tan, D., Kaspar, F., Kaiser-Weiss, A., Swinnen, E., Toté, C., Gregow, H., Manninen, T., Riihelä, A., Calvet, J.-C., Ma, Y., and Wen, J.: An overview of European efforts in generating climate data records, B. Am. Meteorol. Soc., in press, https://doi.org/10.1175/BAMS-D-16-0074.1, 2017.

Vitart, F., Ardilouze, C., Bonet, A., Brookshaw, A., Chen, M., Codorean, C., Déqué, M., Ferranti, L., Fucile, E., Fuentes, M., Hendon, H., Hodgson, J., Kang, H.-S., Kumar, A., Lin, H., Liu, G., Liu, X., Malguzzi, P., Mallas, I., Manoussakis, M., Mastrangelo, D., MacLachlan, C., McLean, P., Minami, A., Mladek, R., Nakazawa, T., Najm, S., Nie, Y., Rixen, M., Robertson, A. W., Ruti, P., Sun, C., Takaya, Y., Tolstykh, M., Venuti, F., Waliser, D., Woolnough, S., Wu, T., Won, D.-J., Xiao, H., Zaripov, R., and Zhang, L.: The Subseasonal to Seasonal (S2S) Prediction Project Database, B. Am. Meteorol. Soc., 98, 163-173, https://doi.org/10.1175/BAMS-D-16-0017.1, 2017. 